\title{
KÖHLMEIER-DEGOS DISEASE (MALIGNANT ATROPHIC PAPULOSIS) AND NEUROLOGIC INVOLVEMENT
}

\author{
Felipe Slaviero', Rafael D'Agostini Annes', Leonardo Frighetto', Lucas Martins Schirmer', \\ José Ricardo Vanzin ${ }^{3}$, Alan Christmann Fröhlich ${ }^{4}$, Jussara Ferraz ${ }^{5}$, Nério Dutra Azambuja Jr. ${ }^{3}$
}

The malignant atrophic papulosis (MAP) was first described by Köhlmeier in 1941 and recognized as a specific entity by Degos in 1942. This rare disorder is an obstructive vasculopathy of unknown origin, characterized by vascular lesions of the skin, central nervous system (CNS) and gastrointestinal tract'. Skin lesions are usually the first manifestation of the disease, although the poor prognosis is resultant of the gastrointestinal and CNS involvement ${ }^{2}$. Once multisystemic disease has developed, death occurs in approximately $50 \%$ of patients within 1 to 2 years, mostly due to intestinal perforation or, less commonly, cerebral infarctions ${ }^{3}$. The neurologic manifestations of MAP include cerebral infarcts, subdural collections, venous sinus thrombosis, polyrradiculoneuropathy, and nonspecific symptoms without objective findings. Myelopathy and myopathy are less frequently reported'.

Since the disease is rare, case reports may contribute to understand its course and response to different approaches. We report a case of delayed diagnosed MAP, highlighting the neurologic involvement, the clinical and histologic patterns to provide its proper diagnosis.

\section{CASE}

A 41-year-old woman was admitted at the hospital because of a 3-year history of an asymptomatic skin rash accompanied by vomiting, constipation, urinary incontinence and neurologic deficits. She had been healthy before the last three years, when she presented a skin rash, initially in the trunk, extended to the lower limbs. The patient had undergone several dermatological evaluations and two skin biopsies of the lesions for histological analysis. Both skin biopsies were misdiagnosed and the patient was treated with systemic corticosteroids, without improvement of the rash. Approximately one year before admission she had began with memory loss. Weakness in the lower limbs and difficulty to walk occurred and were followed by progressive paresis in the left arm, sphincter function abnormalities, and loss of
$15 \mathrm{~kg}$ in the last nine months. The neurologic examination on admission showed spastic tetraparesis, increased muscular reflexes, sustained ankle clonus in the left, bilateral Babinski sign, and left dysmetria in the index-nose test. No papilledema or meningeal signs were present. Skin examination showed a rash with centripetal distribution. The lesions were pink slighted raised papules, surrounded by a pale rim and with a central white dot (Figs 1A and 1B).

The complete blood count, serum biochemistry analysis, renal, hepatic and thyroid function tests were normal. The erythrocyte sedimentation rate was elevated $(36 \mathrm{~mm} / \mathrm{hr})$. Evaluation of the cerebrospinal fluid (CSF) revealed only a high protein concentration (104 mg/dl). An upper endoscopy disclosed a severe chronic gastric inflammation, confirmed in the histological study, and a mild erosive duodenitis. Test for $H$. pylori was negative.

Magnetic resonance imaging (MRI) of the brain disclosed a subdural fluid collection with dural enhancement, and ischemic changes (Fig 2). Spinal MRI showed no abnormalities in the cervical and thoracic cord. A third skin biopsy specimen of the abdomen confirmed the diagnosis of MAP (Figs $1 C$ and 1D).

Initial treatment was performed with $325 \mathrm{mg}$ of aspirin once a day, $250 \mathrm{mg}$ of ticlopidine twice a day, physiotherapy and psychological support. The patient was discharged with partial recovery of the skin rash, although no improvement in the neurological status was observed. She has been accompanied in an outpatient setting during 18 months after the discharge.

A written informed consent was obtained from the patient for the publication of this paper.

\section{DISCUSSION}

The three most accepted theories for the abnormalities of MAP are vasculitis, coagulopathy, and primary disorder of endothelial cells ${ }^{4}$. Usually, the pathology of CNS involvement in a patient with MAP includes disseminated occlusive vasculopathy and the resulting diffuse ischemic changes ${ }^{2}$. About $75 \%$ of the patients are male and

\section{DOENÇA DE KÖHLMEIER-DEgOS (PAPULOSE ATRÓFICA MALIGNA) E ENVOLVIMENTO NEUROLÓGICO}

Neurology and Neurosurgery Service, Passo Fundo RS, Brazil: 'Medical Student, Passo Fundo School of Medicine; ${ }^{2}$ Resident in Neurosurgery, Hospital São Vicente de Paulo, Passo Fundo; ${ }^{3}$ Neurosurgeon, Neurology and Neurosurgery Service; ${ }^{4}$ Neurologist, Neurology and Neurosurgery Service; ${ }^{5}$ Dermatologist, Hospital São Vicente de Paulo, Passo Fundo.

Received 19 December 2008, received in final form 25 March 2009. Accepted 25 May 2009.

Dr. Felipe Slaviero - Serviço de Neurologia e Neurocirurgia - Rua Teixeira Soares 640 - 99010-901 Passo Fundo RS - Brasil. E-mail: felipeslavier@yahoo.com.br 


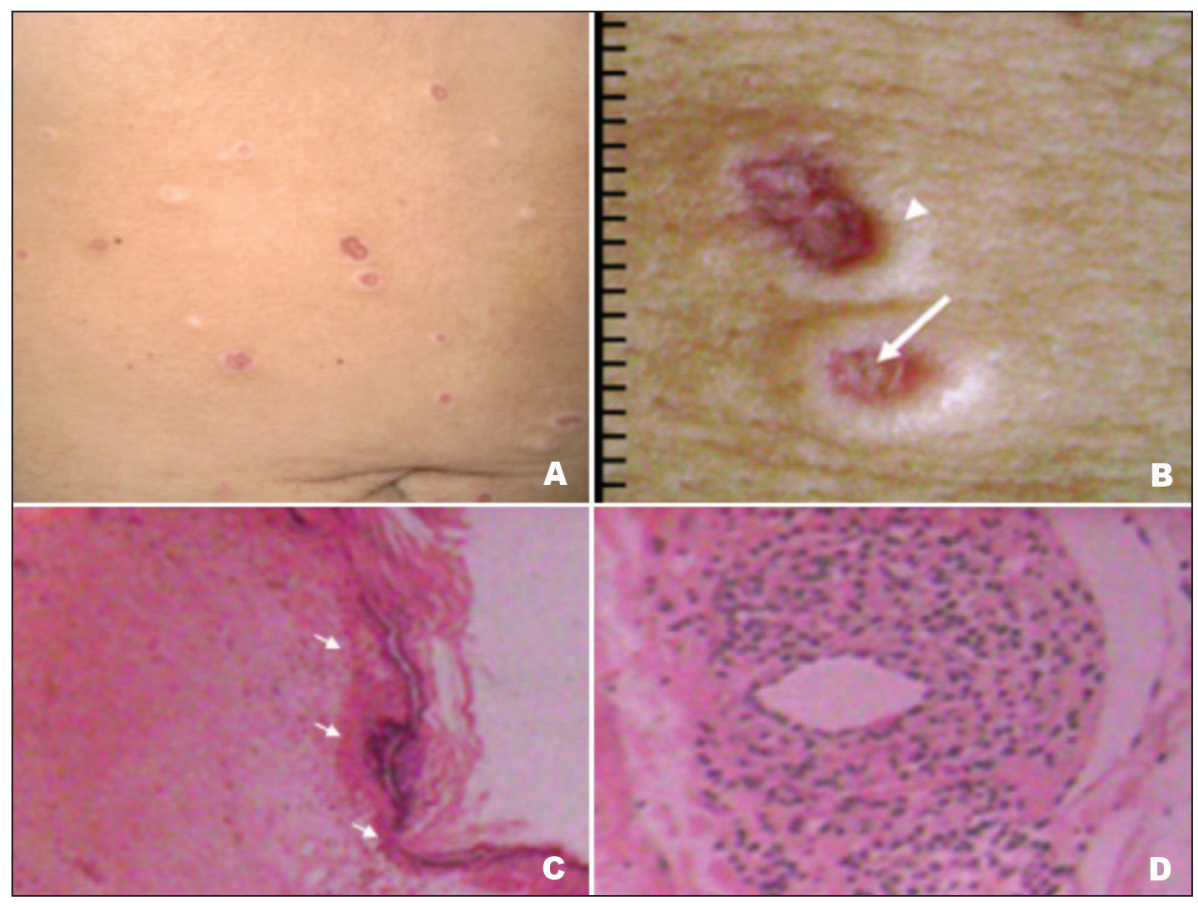

Fig 1. [A] Abdominal skin lesions characterized by erythematous papules, between 2 to $6 \mathrm{~mm}$ in diameter. [B] Amplification of two lesions showing pink slighted raised papules, surrounded by a pale rim (arrowhead) and with a central white dot (arrow). [C] Skin lesion specimen demonstrates absence of crests and atrophic epidermis (arrows). [D] Amplification of the skin lesion specimen demonstrates intense perivascular inflammatory infiltrate (Hematoxylin \& Eosin).
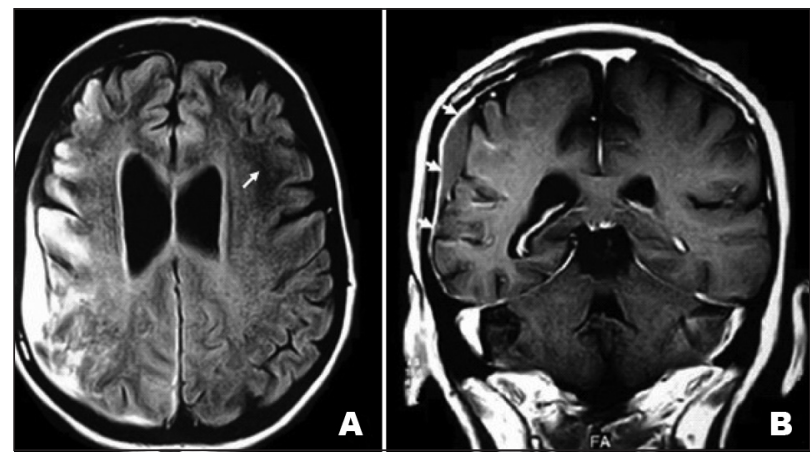

Fig 2. [A] FLAIR axial MRI discloses a right parietal hyperintense subdural collection. Ischemic changes can be noted in the left frontal white matter (arrow). [B] Contrast-enhanced coronal T7-weighted image demonstrates dural enhancement (arrows) and the subdural collection.

the disease is most frequently in the third and fourth decades of life ${ }^{5}$.

The MAP is characterized, at the beginning, by typical skin lesions with papulous aspect, erythematous rim, and white porcelain like atrophic center, localized over the trunk and the lower limbs'. They can develop at any site, although the face, palms and soles are typically spared ${ }^{5}$. Involvement of the gastrointestinal tract is observed in approximately half of the patients and small infarctions in the mucosa can cause perforation and resulting peritonitis, which is the leading cause of death ${ }^{6}$.
In our case, the brain MRI showed a hyperintense subdural collection, indicating a high protein content, and also, abnormal dural enhancement with ischemic changes. This MRI pattern and the high protein level in the CSF suggest a chronic meningovascular process ${ }^{1,7}$. The neuroimaging findings and the clinical diffuse compromising of CNS functions, skin, and gastrointestinal tract implied a systemic abnormality of the microvasculature.

The uncommon frequency of MAP is undoubtedly a challenge for its early recognizing. The differential diagnosis is broad, although the clinical and histologic patterns of the skin lesions are diagnostic. In the present case report, skin lesions preceded the gastrointestinal and neurologic manifestations, and were typical.

Despite the unusual occurrence, the evidence of the classical skin lesions must raise the possibility of the diagnosis, especially when multifocal neurological deficits and systemic compromising are present. The pathologist must know this situation for the histopathological analysis and should be aware of the clinical picture.

Although there is no specific therapy for MAP, cases have responded well to the use of antiplatelets drugs ${ }^{8}$. Heparin has been utilized in the acutely ill, but other anticoagulants, fibrinolytic and immunosuppressive agents have been tried without success ${ }^{5,8}$. Recently, a case report advocated the use of bevacizumab, a recombinant human monoclonal antibody, directed against the vas- 
cular endothelial growth factor, with indirectly evidences of success ${ }^{7}$. The systemic corticosteroids are useless and have been associated with early intestinal perforation and sepsis?.

The disease limited to the skin may have a more benign course, but this is not the most common presentation $^{10}$. Only about $15 \%$ of patients with MAP enjoy good health, with their lesions limited to the skin without any serious events in the gastrointestinal tract or $\mathrm{CNS}^{4,8}$. Furthermore, the disease is usually fatal within three years of the onset of systemic involvement ${ }^{6}$.

In the face of the poor prognosis, additional studies are necessary to supply information about the mechanisms of disease, and therefore, more specific and effective treatment alternatives.

\section{REFERENCES}

1. Amato C, Ferri R, Elia M, et al. Nervous system involvement in Degos disease. Am J Neuroradiol 2005;26:646-649.
2. Matsuura F, Makino K, Fukushima T, et al. Optic nerve and spinal cord manifestations of malignant atrophic papulosis (Degos disease). J Neurol Neurosurg Psychiatry 2006;77:260-262.

3. Loewe R, Palatin M, Petzelbauer P. Degos disease with an inconspicuous clinical course. J Eur Acad Dermatol Venereol 2005;19:477-480.

4. Ball E, Newburger A, Ackerman AB. Degos' disease: a distinctive pattern of disease, chiefly of lupus erythematosus, and not a specific disease per se. Am J Dermatopathol 2003;25:308-320.

5. Chave TA, Varma S, Patel GK, Knight AG. Malignant atrophic papulosis (Degos' disease): clinicopathological correlations. J Eur Acad Dermatol Venereol 2001;15:43-45.

6. Valverde FMG, Pina FM, Ruiz JA, et al. Presentation of Degos syndrome as acute small-bowel perforation. Arch Surg 2003;138:57-58.

7. Caviness VS Jr., Sagar P, Israel EJ, Mackool BT, Grabowski EF, Frosch MP. Case 38-2006: a 5-year-old boy with headache and abdominal pain. N Engl J Med 2006;355:2575-2584.

8. High WA, Aranda J, Patel SB, Cockerell CJ, Costner MI. Is Degos' disease a clinical and histological end point rather than a specific disease? J Am Acad Dermatol 2004;50:895-899.

9. Yukiiri K, Mizushige K, Ueda T, et al. Degos' disease with constrictive pericarditis: a case report. Jpn Circ J 2000;64:464-467.

10. Liu CM, Harris RM, Hansen CD. Lesions resembling malignant atrophic papulosis in a patient with progressive systemic sclerosis. Cutis 2005;75:101-104. 